\title{
Respostas públicas, sucesso e fracasso no gerenciamento de riscos ${ }^{*}$
}

\section{Public responses, sucess and failure in risk managements}

\author{
Monica STEFFEN**
}

\begin{abstract}
RESUMO
Nos anos 80. um acidente médico produziu escândalos políticos em vários países industrializados. Em outros, no entanto, o mesmo problema passou quase despercebido. A contaminação massiva de hemofĩlicos e de destinatários de transfusào de sangue pelo vírus IIIV fornece um exemplo interessante da gestão dos riscos numa escala internacional, com um rol extremamente largo de reaçôes públicas e de políticas face aos riscos de saúde pública. Por que as respostas públicas ao risco são diferentes? Em primeiro lugar, o potencial de mobilização pública é particularmente importante nos domínios carregados de fortes valores simbólicos, como a medicina, o sangue e outros fluídos essenciais. Em segundo lugar, as dificuldades na tomada de decisão e no estabelecimento de estratégias de redução de riscos podem ser ligadas a fatores institucionais que podem atrasar o processo. Finalmente. a avaliaçào do sucesso e do fracasso na gestão dos riscos deve ser distinta segundo o nivel técnico e o nível político da resolução dos problemas. Os argumentos desenvolvidos aqui resultam em grande parte de uma comparação internacional das políticas que concernem ao risco HIV no setor da transfusão sangüínea. A primeira parte do artigo apresenta as abordagens e os conceitos das ciências sociais que permitem compreender as variações das respostas públicas face ao alerta sobre o risco. A segunda parte concentra-se nos elementos particulares do exemplo da transfusão sangüínea e mostra seu signilicado geral para a gestão dos riscos.

Palavras-chave: resposta públicas ao risco. contaminação pelo vírus IIIV em transfusões sangüíneas, variações na gestão de riscos
\end{abstract}

\section{RÉSUMÉ}

Pendant les années 80. un accident médical a conduit à des scandales politiques dans plusieurs pays industrialisés. Dans d'autres cependant le même problème est passé presque inaperçu. La contamination massive des hémophiles et des destinataires de transfusion sanguine par le virus HIV fournit un exemple intéressant de gestion des risques sur une échelle internationale, avec un éventail extrêmement large de réactions publiques et politiques face aux risques sanitaires. Pourquoi les réponses publiques au risque sont-elles différentes? Afin de répondre à cette question, trois arguments seront développés ici. D'abord. le potenticl de mobilisation publique est particulièrement important dans les domaines chargés de fortes valeurs symboliques, telles que la médecine, le sang et d'autres fluides essentiels. Deuxièmement, les

* Tradução de Mariza Riva de Ameida, Departamento de Letras Listrangeiras Modemas, UFPR

** Direlora de Pesquisa, CNRS (França), Institut d'Eludes Politiques de Grenoble, CERAT. Université Pierre Mendes France, B.P. 48,38048 Grenoble Cedez 9, France. monikasteffendomi-grenoble fi 
difficultés dans la prise de décision et dans la mise en oeuvre de stratégies de réduction des risques peuvent être reliés et freinés par des facteurs institutionnels. Troisièmement, l'évaluation du succès et de l'échec dans la gestion des risques doit être distinguée selon le niveau technique et le niveau politique de la résolution des problèmes. Les arguments développés ici résultent en grande partie d'une comparaison internationale des politiques concernant le risque HIV dans le secteur de la transfusion sanguine. La première partie présente des approches et des concepts des sciences sociales permettant de comprendre les variations des réponses publiques face à l'alerte sur le risque. La deuxième partie se concentre sur les éléments particuliers de l'exemple de transfusion sanguine et montre leur signification générale pour la gestion des risques.

Mots-clé: réponses publiques au risque, contamination par le virus HIV des destinataires de transfusions sanguines, varations dans la gestion des risques

\section{ABSTRACT}

During the eighties, a medical accident led to political scandals in several industrialised countries. In others however the same problem went nearly unnoticed. The massive HIV-contamination of haemophiliacs and blood transfusion recipients provides an interesting example of risk management on an international scale. with an extremely wide range of public and political reactions to health risks. Why do public responses to risk vary? In order to answer this question, three arguments will be developed here. First, the potential of public mobilisation is particularly high in fields laden with symbolic values, such as medicine, blood and other vital fluids. Second. the difficulties in decision-making and in the implementation of risk reducing strategies can be traced back to institutional factors. Third, assessment of success and failure in risk management has to distinguish between the technical level and the political level of problem solving. The arguments developed here result to a large extent from an international policy comparison concerning the HIV-risk in the blood transfusion sector. The first part presents approaches and concepts from social sciences towards understanding the variations in public responses to risk alarm. The second part focuses on particular elements from the blood transfusion example and shows their general significance for risk management.

Key-words: public reactions to risk, HIV-contamination of blood transfusion recipients, variations in risk management

Nos anos 80 um acidente médico causou escândalos políticos em diversos países industrializados. Em outros países, no entanto, o mesmo problema passou quase despercebido. A contaminação em massa de hemofílicos e de receptores de transfusões de sangue pelo vírus $\mathrm{HIV}^{1}$ é um exemplo interessante de gerenciamento de riscos em uma escala internacional, com uma grande variação nas reações da população e nas políticas que tratam dos riscos à saúde pública. Por que as reações públicas ao risco variam? A fim de se responder a essa pergunta, três argumentos serão colocados. Primeiramente, o potencial da mobilização pública é particularmente alto nas áreas com alto teor de valor simbólico, tais como as de medicamentos, sangue e outros fluidos vitais. Em segundo lugar, as dificuldades na tomada de decisões e na implementação de estratégias de redução de riscos podem ser remontadas a fatores institucionais. Terceiro, a avaliação do sucesso e do fracasso no gerenciamento de riscos deve levar em conta que existem dois níveis (técnico e político) para a solução de problemas. Os argumentos desenvolvidos aqui resultam em grande parte de uma comparação política internacional referente ao risco do vírus HIV no setor de transfusão de sangue. A primeira parte trata de abordagens e conceitos de ciências sociais voltados ao entendimento das variações nas reações públicas com respei- 
to ao alarme de risco. A segunda enfoca clementos particulares do exemplo da transfusão de sangue e mostra seus significados para o gerenciamento de riscos.

\section{Reações públicas, gerenciamento de programas e gerenciamento político}

O campo da tecnologia e da saúde confronta o observador com duas evidências. De um lado, em sociedades avançadas, a opinião pública tende a ser mais sensivel aos riscos do que aos benefícios do progresso técnico, embora estes sejam medidos em termos de aumento da expectativa de vida enquanto os riscos freqüentemente permanecem controversos. Por outro lado, as reações públicas voltadas aos riscos parecem ser imprevisíveis. Elas variam de acordo com o campo em que os riscos são esperados ou provávcis. O transporte rodoviário, os materiais de construção, a agricultura e a indústria modernas oferecem um número de riscos bastante conhecidos que para o público assumem a forma de acidentes de carro, patologias do amianto e poluição. Ainda assim, esses riscos são em grande parte aceitos c costumam gerar somente manifestações locais. Inversamente, os riscos no fornecimento de medicamentos ou de comida geram ondas de protestos nacionais $\mathrm{e}$ até mesmo internacionais. O escândalo da transfusão de sangue, o escândalo ESB (doença da vaca louca) e o escândalo dos agrotóxicos estão entre exemplos recentes. A percepção de riscos na opinião pública e as reações das políticas públicas que resultam dessa percepção também diferem consideravelmente de um país para o outro, incluindo nações vizinhas que partilham de um nível comum de desenvolvimento econômico, cultural e social. A enorme contaminação de hemofílicos pelo vírus HIV levou a um escândalo político na França, cnquanto na Espanha e na Itália não houve manifestação pública, nem por parte da mídia e nem das associações de hemofilicos. ${ }^{2}$ A Alemanha e a França apresentam surprecndentes distinções com relação ao tema energia nuclear. Na Alemanha, o repúdio aos riscos nucleares deu ascensão a um Partido Verde relativamente poderoso e a uma ação militante espetacular. Na França, nem a política oficial de energia nuclear dos últimos 30 anos, nem o acidente de Chernobyl levaram a uma manifestação comparável. Além disso, o nível das reações públicas aos riscos não parece estar relacionado à natureza do risco ou acidente, à severidade do possível dano, às conseqüências a longo prazo ou à extensão geográfica. $\mathrm{O}$ grau da reação pública também não reflete a eficiência ou a ineficiência no gerenciamento de riscos.

A discrepância entre as reações públicas aos riscos e os fatores que caracterizam um risco ou acidente é freqüentemente entendida como um problema de subjetividade versus objetividade. No entanto, as ciências sociais oferecem várias abordagens e conceitos para explicar tais reações divergentes. Certas ferramentas teóricas, que podem ser úteis neste contexto, nos são fornecidas por Boven, 't Hart e Peters. ${ }^{3}$ Estes autores classificam dois níveis no gerenciamento de problemas públicos: o nível "programático" e o nível "político". Aplicado ao gerenciamento de riscos, o nível programático refere-se ao tratamento prático, técnico e institucional de um dado risco ou acidente: agrimensura, sistemas de coleta de informações e dados, tomada de decisões nas medidas que visam a controlar e eliminar o risco ou resolver as consequiências de um acidente, e reformas que visam a prevenir situações de risco semethantes no futuro. Essa parte programática no gerenciamento de riscos passa por duas fases. O problema primeiramente deve ser identificado. Soa-se o alarme. Logo após, decisões precisam ser tomadas e implementadas, avaliadas e reajustadas. A tomada de decisões e a implementação, no entanto, precisam ser específicas em cada caso por causa das diferenças no contexto institucional, legal e financeiro. O nível do "gerenciamento de riscos político" refere-se às maneiras pelas quais o programa de gerenciamento de riscos foi aceito pela opinião pública, pela mídia, pelos interesses organizados e pelas forças políticas. As posturas freqüentemente mudam com o passar do tempo. Os ju\}gamentos podem ser positivos no início para tornaremse críticos posteriormente ou, inversamente, podem evoluir de um protesto inicial a uma aceitação gradual ou final.

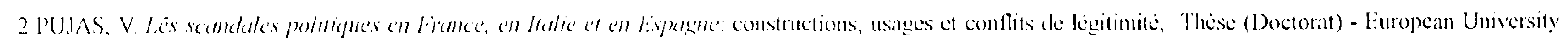
Institute, Horence 1999.

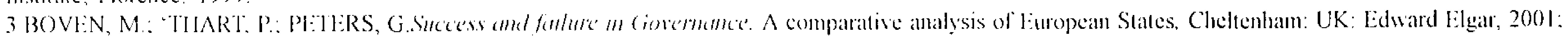

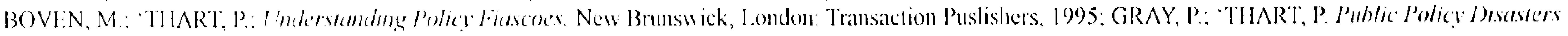
in Hiskm limome. Iondon. New York: Routledge, 1998. 
Os agentes implicados e as referências utilizadas nos dois níveis são evidentemente diferentes. O gerenciamento programático de riscos depende de conhecimento científico, de peritos técnicos, de instituições, de habilidades de coordenação e de provisão financeira. $O$ gerenciamento político de riscos depende de redes e valores sociais mais amplos, de regras legais, da comunicação pública, da mídia e da organização do sistema político global. Fatores adicionais que são importantes e dão forma ao nível político do gerenciamento de riscos são os modos pelos quais uma sociedade permite a expressão das manifestações. A crítica pode ser conduzida nos casos de tomada de decisões e as políticas públicas atentam para as manifestações públicas.

Os gerenciamentos programáticos e políticos podem coincidir. Ambos podem ser tanto apropriados como nocivos. No primeiro caso, uma revisão do gerenciamento de riscos anterior é improvável porque faltam pressões e incentivos para uma mudança. No segundo caso, críticas vindas de peritos e do público sobre o gerenciamento de riscos vigente podem dar início a reformas. Por outro lado, os gerenciamentos político e programático podem não coincidir. Um gerenciamento de riscos programático ruim pode ser acompanhado por um gerenciamento político bastante eficiente. Essa aceitação da sociedade de um mau gerenciamento de riscos técnicos pode estar baseada na ignorância e na fatalidade, no fato de outras prioridades ocuparem a atenção pública ou meramente no fato de informações relativas ao risco estarem sendo mantidas em segredo.

O caso mais interessante é a combinação de um gerenciamento de riscos programático relativamente bom com um mau gerenciamento político. Tais casos significam que o fator de risco foi reavaliado posteriormente, à luz de uma nova percepção do risco. Essa situação geralmente ocorre quando um risco que foi inicialmente considerado como mínimo, de somente uma natureza possível e com conseqüências insignificantes, é seguido de um acidente grave. Em termos mais gerais, sempre que as conseqüências de um risco tornam-se visíveis ou provam-se mais sérias do que se pensava originalmente, a história será relida de uma perspectiva diferente. Uma experiência concreta das consequiências é um fator importante na mudança de posturas. O que parecia aceitável anteriormente é agora rejeitado como um escândalo intolerável. Além disso, quando o problema dado inclui dimensões morais - tais como crença, confiança ou solidariedade - o público sente-se "traido", e clama por "justiça" em termos de condenação legal, explicação pública e compensação financeira para as vitimas.

Alguns sociólogos identificaram os principais fatores que determinam a percepção de riscos e a manifestação pública. Quando esses fatores estão insuficientemente presentes em um dado contexto, os riscos existentes podem não ser notados. Os riscos percebidos não necessariamente melhoram a manifestação e as manifestações podem não chamar a atenção da sociedade. Os processos de percepção de riscos e manifestação pública dependem de fenômenos sociológicos e institucionais. Mesmo dentro da comunidade científica, a percepção de riscos é de certo modo construida socialmente. Três elementos são essenciais para uma percepção de riscos eficaz. ${ }^{+} \mathrm{O}$ risco tem que ser especificado por um grupo ou indivíduos providos de "legítima autoridade para definir e descrever o perigo". Por exemplo, a autoridade em saúde pública é comumente atribuida a peritos médicos e científicos. O segundo elemento é "a afirmação de uma cadeia causal que explique o perigo". Os riscos têm que ser remontados a uma causa, que é compatível com o estado de conhecimento da sociedade em questão. A "designação de possíveis vítimas" constitui o terceiro elemento. ${ }^{5}$

Ao analisar a mobilização, o estabelecimento das pautas e as políticas públicas, sociólogos e cientistas políticos observaram se um risco percebido pode ou não inflamar as reações públicas e as manifestações. Determinaram assim as condições gerais de protesto para riscos possíveis. O trabalho de Boltanski sobre o processo de denúncia é diretamente relevante ao assunto. "De acordo com este autor, manifestações e mobilização social somente surgirão quando o risco ou acidente estiver "socialmente visível", o que significa que tem que haver vítimas reconhecidas. A segunda condição é que as vítimas protestem "coletivamente". As vítimas têm que ser estabelecidas como um grupo reconhecido e também têm que visar à expressão de suas queixas. A epidemia de Aids fornece um exemplo interessante desse fenômeno. Grande pressão pública originou-se das organizações homossexuais, a favor de uma política de proteção ao anonimato e à privacidade. Outras vitimas da epidemia foram menos organizadas e tiveram bem menos in-

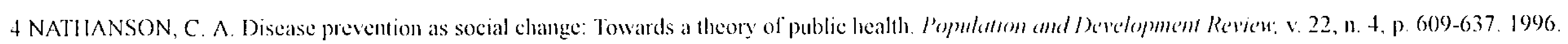
5 Ibid., p. 615. 
fluência sobre a orientação política. ${ }^{7}$ A comunidade homossexual tem sido muito eficaz na definição e na denúncia sobre o risco social da estigmatização. Ao contrário, viciados em drogas intravenosas e pacientes receptores de transfusões de sangue foram bem menos capazes de exprimir o risco vital de serem contaminados pelo vírus HIV. Embora os hemofílicos tenham constituído uma comunidade bem organizada em cada um de seus paises assim como no mundo todo, eles constituíram um agente político bem menos autônomo porque suas associações eram fortemente ligadas aos bancos de sangue e eram designadas por peritos médicos. Além disso, os hemofílicos preferiram uma postura discreta a respeito do risco do vírus HIV, temendo reações negativas do seu ambiente social. Por todas essas razões, a seleção de doadores de sangue permaneceu insuficientemente severa e o acesso aos fatores de coagulação do vírus inativo permaneceu limitado em vários países. A terceira condição para uma manifestação pública eficaz, na opinião de Boltanski, é a questão da generalização. O problema do risco tem que atrair maior interesse público. Somente quando partes importantes da opinião pública são capazes de identificar-se com o problema, este se torna um problema geral capaz de encorajar reações públicas eficientes.

Em teorias psicanalíticas, o escândalo é a forte expressão de indignação originada por um sentimento de injustiça inaceitável e endereçada a terceiros a fim de envolvê-los e assim obter auxílio. Uma reação positiva de um terceiro é vista nestas teorias como motivada por um interesse pessoal, enraizado na própria história do terceiro. Escândalos públicos aparecem, assim, como o resultado de uma aliança imprevisível. O escândalo do sangue na França fornece elementos que sustentam essa visão. Champagne e Marchetti ${ }^{x}$ mostraram que a campanha da mídia francesa contra os executivos do sistema de transfusão de sangue foi resultafo de uma interessante aliança entre, de um lado, hemofilicos franceses desiludidos com as dificuldades encontradas ao reivindicarem indenização e, do outro lado, jovens jornalistas representando uma nova geração de profissionais à procura de oportunidades para ampliar seu campo de ativi- dade. Investigar um setor médico um tanto restrito deu a oportunidade de ocuparem novas posições no jornalismo médico, um campo tradicionalmente reservado para médicos, na França. De acordo com essa visão, as especificidades organizacionais do sistema de hemofilia francês e da imprensa francesa forneceram os ingredientes para um escândalo extraordinário. A revelação de informações e de muitos documentos confidenciais, tornados públicos pelos jornalistas, coincidiu, no final dos anos 80 , com um crescente descontentamento da opinião pública com relação à instituição política e à elite. Um sentimento de conspiração amplamente compartithado transformou um problema médico em um escândalo político.

\section{Fatores especificos e o significado geral do es- cândalo do sangue}

O gerenciamento de riscos do vírus HIV no plasma e nos sistemas de transfusão de sangue mostrou-se bastante diverso em diferentes países. Um grupo internacional de pesquisa liderado por Feldman e Bayer conduziu uma ampla comparação, baseada em 11 países desenvolvidos e um confronto preliminar com países africanos e asiáticos. " Os resultados isolam fatores estratégicos tanto na percepção pública de riscos quanto no sucesso ou fracasso do gerenciamento de riscos, no plano programático assim como no plano político. Lições podem ser tiradas do caso específico do sangue para todo o campo de tecnologia da saúde. O caso mostrou a importância do contexto institucional, num sentido amplo, excedendo as instituições de saúde.

Nos anos 80 , perto de 10 mil hemofílicos e um número igual de receptores de transfusão de sangue foram contaminados pelo vírus HIV na União Européia. Isso gerou mais vítimas do que qualquer outro acidente identificado na Europa desde a Segunda Guerra Mundial: 20 mil, dos quais metade morreu. O acidente foi ligado ao rápido desenvolvimento de novas tecnologias na indústria de processamento de plasma. Novos fatores altamente concentrados de coagulação permitiram aos paci-

6 BOLTANSKI, L. I.a dénonciation. Acres de la recherche en sciences socides. n. 51, p. 3-40, mar. 1984

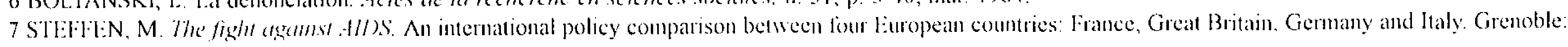
Presses Universitaires de Grenoble, 1996.

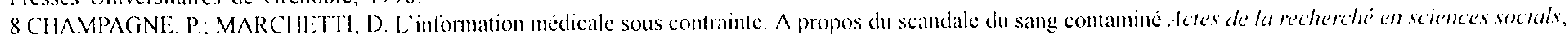
p. $40-62$, p. 101-102, mars 1994. 
entes tratarem de sua hemofilia de uma maneira preventiva, e assim viverem normalmente sem deficiências patológicas. A enorme produção de medicamentos começou no final dos anos 70 alcançando capacidade máxima no começo dos anos 80 . O desenvolvimento coincidiu com as fases iniciais da epidemia de Aids, quando a extensão desta não era completamente identificada e não havia ainda nenhum teste para prevenir doações de sangue infectado pelo vírus HIV. Milhares de doações de sangue durante o processo de produção multiplicaram o risco de doações de sangue contaminado nas mesmas proporções. ${ }^{10}$

A França montou sua própria indústria nacional e pública de plasma, visando à auto-suficiência e protecionismo econômico. O abastecimento doméstico foi considerado mais seguro do que a importação de produtos da indústria farmacêutica internacional. Ainda assim a França não obteve tanto êxito na proteção de seus hemofílicos como nos países que confiaram no mercado internacional. Além disso, a França chegou a apresentar $60 \%$ de todos os receptores de transfusões contaminados pelo vírus HIV na Europa, por causa de uma incrível deficiência na seleção de doadores. Na verdade, a doação de sangue foi dominada por uma ideologia política pós-guerra, na qual a solidariedade e a independência nacionais, ao invés de segurança médica, foram postas em evidência. Apesar das pesadas penas de prisão já declaradas contra o principal gerenciador do setor de plasma e transfusão de sangue, a última fase dos procedimentos legais ainda continua, quase 20 anos depois dos eventos.

O que é tão específico sobre sangue que possa explicar as veementes reações públicas aos riscos? Como o grupo Feldman/Bayer mostrou, o sangue tem um alto valor simbólico em cada sociedade. $O$ valor atribuído ao sangue, contudo, é profundamente ambíguo, com aspectos positivos e negativos. Do lado positivo sangue significa vida, força, saúde, os próprios filhos, descendência nobre, família, solidariedade e nação. Todos os bons elos entre os membros da humanidade são simbolizados por um bom sangue. Por outro lado, sangue também significa doença, morte, guerra, influências genéticas negativas, estrangeiros e racismo. "Sangue ruim" refere-se àquilo que divide a raça humana e que exclui a vida. Um "risco" ao redor do sangue imediatamente realça o aspecto negativo do simbolismo do sangue. "Sangue ruim" ativa medos antigos e subconscientes e reações quase incontroláveis. Portanto, um risco no sistema de fornecimento de sangue apresenta um alto potencial de escândalo. Um fracasso na tomada de decisões é facilmente entendido como corrupção, considerações econômicas tornam-se dinheiro ruim e informações retidas são vistas como conspiração. $O$ contraste entre a confiança depositada nos serviços médicos e a dolorosa desilusão resultante é sentido como traição.

Esta tendência voltada para o aspecto negativo do simbolismo é provavelmente extensível a todos os riscos que se referem diretamente ao corpo humano: todo o setor de intervenção médica e de produtos farmacêuticos, e também a indústria produtora de comida. O sangue é o fluido mais vital para a sobrevivência biológica do indivíduo. No plano sociológico, os equivalentes são a energia e a água. Um gerenciamento de riscos malsucedido nesses setores pode provocar uma dinâmica parecida voltada para o simbolismo negativo fundamental e, portanto, reações imprevisíveis do público.

Ao mencionar os casos nacionais de contaminação de sangue pelo vírus HIV para a distinção entre os níveis "programático" e "político" do gerenciamento de riscos, a comparação internacional mostrou que maiores diferenças ocorreram no segundo nível. O tratamento político no periodo subsequiente à contaminação variou de nenhuma reação pública a escândalos históricos. Ainda assim todos os paises desenvolvidos obtiveram sucesso ao eliminar o risco de uma enorme infecção em pouco tempo, entre a metade de 1984 e o final de 1985, e com meios parecidos: seleção cuidadosa de doadores, exame sistemático de amostras de sangue e inativação do vírus aplicada aos concentrados de coágulo. Mais tarde, tecnologias genéticas foram desenvolvidas para produzir fatores de coagulação e evitar material biológico perigoso proveniente de sangue humano. A distinção entre o nível técnico e o nível biológico do gerenciamento de riscos, no entanto, é uma ferramenta teórica. Na realidade, os dois níveis não são dissociados um do outro, mas funcionam em um contexto comum. O 
caso do sangue permitiu que elementos-chave sobrepostos fossem isolados e isto ficou bem exemplificado no caso francês.

Na França, os fracassos no nível programático foram todos ligados, de um lado, ao funcionamento interno do setor de plasma e à transfusão de sangue e de outro às crenças coletivas sobre a segurança da doação de sangue gratuita (voluntária). "A seleção de doadores revelou-se muito difícil de se adotar porque perturbou a organização tradicional de coleta de sangue e os hábitos de trabalho nos bancos de sangue. A tão respeitada associação de doadores de sangue usou sua influência moral para limitar as perguntas a serem feitas sobre riscos e comportamento sexuais particulares. A distinta separação entre a vida particular e os assuntos públicos na cultura política francesa aumentou as dificuldades. Além disso, o setor de transfusão de sangue fugiu ao controle. Os corpos institucionais encarregados do setor de transfusões eram chefiados pelos mais renomados profissionais do setor que os próprios eram encarregados do controlar. As autoridades de saúde, quase desprovidas de pessoal, confiaram totalmente nos profissionais para aconselhamento, tomada de decisoes e implementação de soluções. A tutela oficial do Ministério da Saúde mostrou-se, portanto, extremamente fraca, ou ausente. Além disso, medidas para diminuir e finalmente climinar o risco foram adiadas por causa das dificuldades de coordenação no Ministério da Saúde e também no governo.

As maiores falhas nos níveis programático e político do gerenciamento de riscos no caso francês podem ser atribuidas a três elementos. O primeiro foi vinculado à estratégia oficial de minimizar os riscos, durante toda a década de 80, nas politicas gerais de Aids assim como no setor de transfusão. O segundo foi a inquestionável política de auto-suficiência, que combinou um interesse econômico com uma crença na inerente segurança do sistema francês de coleta de sangue. O terceiro elemento foi a recusa em reconhecer os danos causados aos pacientes durante esse período. Como produtos sangüíneos não têm uma posição legal exata na França e não foram classificados como produtos farmacêuticos, eles não se enquadraram no controle normal e nos procedimentos de marketing de medicamentos. Tudo isso levou a uma confusão na percepção de responsabilidade legal. ${ }^{12}$ Essa era uma área obscura, até que, nos anos 90, os tribunais começaram a discutir se sangue e produtos derivados deveriam seguir as mesmas regras de garantia de produto. Portanto, o amparo legal a pacientes que recebiam transfusões de sangue ou medicamentos derivados era incerto e nem sempre bem aceito. Além disso, a organização da lei c dos tribunais franceses em duas vertentes distintas, separando as questões legais particulares e administrativas, tornava os processos legais extremamente difíceis para pacientes tratados nos bancos de sangue públicos. O governo hesitou por muitos anos antes de finalmente conceder, sob pressão de uma escandalosa campanha de opinião pública, uma generosa indenização aos pacientes contaminados pelo vírus HIV. As questões legais foram finalmente resolvidas no tribunal, ratificando a responsabilidade pelos produtos aos bancos de sangue e confirmando também a responsabilidade das autoridades públicas com relação aos possiveis riscos.

As principais falhas no gerenciamento de risco, tanto no nível programático quanto no nível político, estiveram todas vinculadas à debilidade das autoridades de saúde pública e à falta de garantias reconhecidas para as vítimas. Dois elementos institucionais, os graus de independência/ poder organizacional das autoridades responsáveis, e a estrutura do sistema legal de responsabilidades, devem ser considerados como fatoreschave em qualquer gerenciamento de riscos eficiente. Os exemplos britânico e alemão confirmam este argumento. Como muitos outros países, estes não conseguiram proteger seus hemofílicos de uma contaminação massiva, conseguindo porém proteger o sistema geral de transfusão de sangue com considerável sucesso. A forma de seleção dos doadores de sangue foi rapidamente aperfeiçoada nos dois países, sob a autoridade do Serviço Nacional de Saúde na Grã-Bretanha e através da iniciativa privada (Cruz Vermelha) na Alemanha. As autoridades públicas na Grã-Bretanha aceitaram investigações oficiais no gerenciamento de riscos nos centros de transfusão de sangue. Na Alemanha, o controle oficial da indústria do plasma foi reforçado e os pacientes

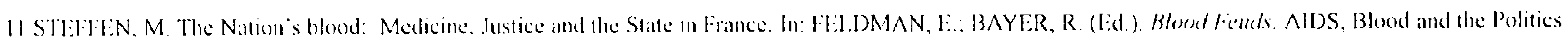
of Medical Disalster. New York: Oxford University Press, 1990.

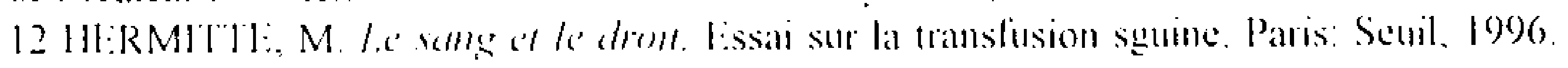


puderam contar com a proteção da lei com respeito aos medicamentos. Isso definiu a responsabilidade dos produtores sobre todas as conseqüências secundárias. Ambos os países finalmente optaram por esquemas de indenização pública bem menos generosos do que o esquema francês, mas que foram realizados em um contexto de negociação com as associações de vítimas, prevenindo assim campanhas públicas em larga escala sobre o assunto.

A comparação internacional forneceu os elementos para a classificação dos casos nacionais de acordo com a intensidade das reações públicas ao risco do HIV/ sangue. ${ }^{13}$ No topo desta classificação estão a França e o Japão com escândalos públicos e políticos de grande alcance, resultando em uma politica de compensação cara, em termos financeiros e políticos. Esses dois paises têm em comum um sistema de governo e uma estrutura de tomada de decisões centralizados, um nível muito baixo de participação dos representantes da população envolvida, e uma cultura governamental de sigilo. $O$ resultado em ambos os casos foi que os estabelecimentos governamentais e médicos foram culpados pelo que não deu certo. Em um nível intermediário estão os Estados Unidos e a Alemanha, que têm em comum um sistema de governo descentralizado, uma indústria privada produtora de plasma e uma estrutura legal que fornece, pelo menos na teoria, o reconhecimento dos direitos de indenização para as vítimas, através de uma lei civil privada nos Estados Unidos e pela lei de medicamentos na Alemanha. A Dinamarca também pode ser incluída na categoria de reações públicas de alcance intermediário. Embora o risco tenha ocasionado uma mobilização extraordinária na opinião pública, o número de vítimas permaneceu muito limitado. No contexto do altamente desenvolvido sistema de previdência social dinamarquês, o acidente pareceu inaceitável para o público e para as forças políticas. Reações públicas de pequeno alcance foram encontradas no Reino Unido, Bélgica e Finlândia. Os dois últimos tinham em comum uma taxa muito baixa de contaminação resultante de um gerenciamento eficiente de riscos técnicos. O muito bem-sucedido gerenciamento político na Grã-Bretanha, apesar da alta taxa de contaminação entre os hemofilicos devido aos produtos importados dos EUA e negociações bastante demoradas para indenização pública, deve ser relacionado à posição de relativo destaque de autoridades da saúde pública no âmbito político, e às capacidades institucionais de coordenação dentro do Sistema Nacional de Saúde.

Nenhum dos paises em desenvolvimento foi palco de reação pública, muito menos de um escândalo público, apesar do fato de muitos receptores de transfusões continuarem sendo contaminados pela Aids além de outras doenças transmissíveis. Os hemofílicos nesses países não tinham nenhum acesso aos novos, porém altamente contaminados, fatores de coagulação, exceto alguns poucos desafortunados que pagaram por seus privilégios sociais e médicos com morte de Aids. Nesses países o simples acesso a um cuidado indispensável ainda é mais relevante do que os riscos que os medicamentos possam trazer. As sociedades e as nações diferenciam-se na exposição, percepção e gerenciamento de riscos.

\section{Conclusão e perspectivas: fixando regras para a arbitragem de riscos}

Os casos empíricos e os elementos teóricos analisados nos capítulos precedentes sugerem duas conclusões e uma proposta de política para o futuro.

A primeira conclusão é que não pode haver um elo direto de causalidade entre riscos e reações públicas. $\mathrm{O}$ desenvolvimento de tecnologia, os resultantes riscos para a saúde e o gerenciamento para controlá-los estão todos situados em um contexto social, político e institucional. As relações de causalidade são necessariamente complexas. O gerenciamento de riscos é mediado por fenômenos sociológicos compostos por várias partes, variando de valores culturais, percepção social de riscos e organização das possiveis ou das presentes vítimas, a estruturas institucionais, regimes de responsabilidade, mecanismos de tomada de decisões e modo como políticas públicas são conduzidas em cada país. Por todas essas razões, as manifestações públicas aos riscos tecnológicos permanecem difíceis de se prever. Elas são dependentes da interação entre os contextos sociais e institucionais em que as situações de risco aparecem.

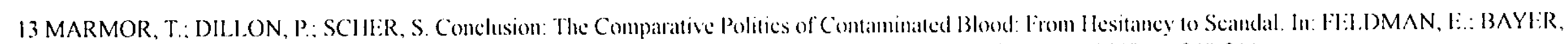
R. (Ed.). Blood liemd. AIDS. Blood and the Politics of Medical Disaster. New York: Oxlord Universily Press, 1999. p. 349-366. 
A segunda conclusão é que em setores específi$\cos$, os riscos levam mais freqüentemente à reação pública do que em outros setores. Os setores médico e farmacêutico estão particularmente expostos a manifestações que geram grande atenção. A provisão de alimentos, água e energia deve ser considerada como campo onde o potencial de contestação pública também é importante. Ainda assim deve-se tratar o assunto com cautela. A exigência social por medicamentos seguros e por outros serviços fundamentais preocupa os países onde a saúde é vista como um direito básico do cidadão. Nesses países, as autoridades públicas são responsabilizadas pela saúde e segurança públicas. Isso caracteriza as democracias modernas, particularmente as previdências sociais européias. Nos países em desenvolvimento, a escala de prioridades é provavelmente diferente, sendo o acesso aos medicamentos e a outros bens vitais de primordial importância. O desenvolvimento econômico, especialmente nesses últimos países, não deveria ser medido somente através de taxas de crescimento econômico, mas deveria incluir referências ao crescimento nacional de riscos domésticos.

As perspectivas futuras nos campos da tecnologia e do gerenciamento de riscos requerem uma participação mais democrática, estruturas de consulta eficazes e regras para negociação da prevenção e da aceitação de riscos. Isto contribuiria para a implementação do princípio geral da precaução que, de outro modo, pode permanecer como um ideal não realista, especialmente na confrontação globalizada entre Norte e Sul. A transformação em diretrizes práticas e legais deveria iniciar com o questionamento sobre quem sustenta os possíveis riscos, e como a participação das possíveis vítimas na to-

\section{REFERÊNCIAS}

BOLTANSKI, L. La dénonciation. Actes de la recherche en sciences sociales, n. 51. p. 3-40, mars 1984.

BOVEN. M.: THART. P.: PETERS. G. Success and failure in Governance. A comparative analysis of European States. Cheltenham, UK: Edward Elgar. 2001.

BOVI:N. M.: 'THIART. P. Understanding Policy Fiascoes. London: Transaction P'uslishers. New Brunswick. 1995. mada de decisões no gerenciamento de riscos deveria ser organizada. As garantias legais que protegem as vítimas, no caso dos riscos se tornarem reais, deveriam constar dos acordos desde o início. O problema mencionado aqui refere-se à equiidade na exposição, na prevenção e na compensação aos riscos.

Assim como a precaução, a eqüidade é um princípio geral difícil de implementar, porque necessita de um compromisso moral bem como de regras precisas e compulsórias. O contexto da globalização econômica também tem que ser levado em conta. Fóruns internacionais deveriam fixar diretrizes para os criadores e legisladores de políticas enfatizando o respeito às possíveis vítimas, com o principal objetivo de garantir seus direitos a cuidados adequados e indenização no caso de danos. O reconhecimento e esclarecimento prévios tornariam a aceitação de riscos, que eram considerados inevitáveis, não somente mais fáceis como também mais justos. Cada ramo da indústria e da tecnologia deve negociar um conjunto coerente de diretrizes para a "arbitragem de riscos" a fim de determinar modos pelos quais divergências sobre avaliação, distribuição e gerenciamento de riscos deveriam ser solucionadas.

A maior lição do caso HIV/sangue é a seguinte: o problema chave não foi a contaminação ter acontecido, já que isto é em parte inevitável, mas sim que regras sobre como lidar com riscos inesperados e suas dramáticas conseqüências não existiam na maioria dos países. A enorme contaminação e a censura política foram o resultado dessa falta de regras. Um gerenciamento de riscos bem-sucedido depende em grande parte de informações adequadas sobre as possiveis vitimas e de regras reconhecidamente legítimas para arbitragem de riscos.
CHIAMPAGNE. P.; MARCIIETTI, D. L'information médicale sous contrainte. A propos du scandale du sang contaminé. Actes de la recherché en sciences socials, p. 40-62, p. 101-102. mars. 1994.

FELDM $\Lambda$ N. E.; BAYER, R. (Ed.). Blood Feuds. Aids, Blood and the Polities of Medical Disaster. New York: Oxford University Press. 1999. 
GRAY, P.; 'THART, P. Public Policy Disasters in Western Europe. London, New York: Routledge, 1998.

HERMITTE. M. Le sang et le droit. Essai sur la transfusion sguine. Paris: Seuil, 1996.

MARMOR, T.; DILLON, P.; SCHER, S. Conclusion: The Comparative Politics of Contaminated Blood: From Hesitancy to Scandal. In: FELDMAN, E.; BAYER, R. (Ed.). Blood Feuds. Aids, Blood and the Politics of Medical Disaster. New York: Oxford University Press, 1999. p. 349-366.

NATHANSON, C. A. Disease prevention as social change: Towards a theory of public health. Population and Development Review, v. 22, n. 4, p. 609-637, 1996.
PUJAS, V. Lês scandales politiques en France, en Italie et en Espagne: constructions, usages et conflits de légitimité. Thèse (Doctorat) - European University Institute. Florence, 1999.

STEFFEN, M. The fight against Aids. An international policy comparison between four European countries. France, Great Britain, Germany and Italy. Grenoble: Presses Universitaires de Grenoble. 1996.

STEFFEN, M. The Nation's blood: Medicine, Justice and the State in France. In: FELDMAN, E.; BAYER, R. (Ed.). Blood Feuds. Aids. Blood and the Politics of Medical Disaster. New York: Oxford University Press, 1999. p. 96-126. 